\title{
THE SPECIAL TAX REGIME AS A FACTOR OF BUSINESS ACTIVITY IN MODERN RUSSIA
}

\author{
Svetlana Gorbushina \\ Saint Petersburg State University \\ Dyukina Tatiana \\ Saint Petersburg State University
}

\begin{abstract}
The research is based on the hypothesis that different special tax regimes have non-identical impact on the level of entrepreneurial activity. Special tax regimes, combined with the actual conditions of individual entrepreneurs, as well as a variety of contributing factors can form a special business environment, which in varying degrees, is suitable for business purposes, varying in the range of extremely unfavorable to very favorable. On the basis of empirical data on special tax regimes established influence, as well as its strength, on the level of entrepreneurial activity in the private business sector in Russia.
\end{abstract}

Keywords: special tax regimes, individual entrepreneurs, entrepreneurial environment, entrepreneurial activities

JEL code: $\mathrm{H} 21$

\section{Introduction}

The most important element of the dynamic development of almost all countries deservedly serves small businesses, which contributes to the formation of the competitive environment, the creation of additional jobs, the saturation of the market with various goods and services. In modern Russia, a significant role is played by small businesses as a structural component of the economy with a high potential of entrepreneurial initiative and effectiveness. It attaches special importance to its regulatory instruments. The research is based on an assessment of the relationship of special tax regimes and the level of entrepreneurial activity. The study is based on state statistical reporting materials using statistical methods of information processing (analytical categories, a number of dynamic, analysis of variation, correlation and regression analysis, graphical methods).

\section{Status and regulation of small business in Russia}

In the context of the radical transformations of modern Russian small business is regarded as one of the factors of innovation development, improving economic structure, ensuring a high level of sustainable employment (Development Strategy ..., 2016). And it is quite reasonable, since small businesses are inherent traits: a special sensitivity to market conditions, flexibility and agility in terms of development of new industries and markets, including on the basis of innovation, the maximum realization of human creativity.

The importance of this kind of business in Russia is not comparable with those of developed industrial and post-industrial countries. In Russia, only $25 \%$ of the employed population works in small and medium-sized enterprises (SMEs), while in OECD countries, this figure varies on average from $35 \%$ to $80 \%$ (Economic Survey, 2014). It shows, first of all, the adverse business climate and lack of access to finance.

A specific feature of small business, which is based on the combination in one person of the owner and manager, on the one hand increases the risk, and therefore dependent on the quality 
of institutional support for the market, and on the other - always encourage the search for adequate solutions. Particularly acute is manifested in the individual business format, when a citizen is engaged in entrepreneurial activities without forming a legal entity and without the involvement of hired labor and the risk with all its assets. However, as a condition of selfrealization, this form of employment is becoming very attractive for the majority of the population in Russia (Fig. 1).

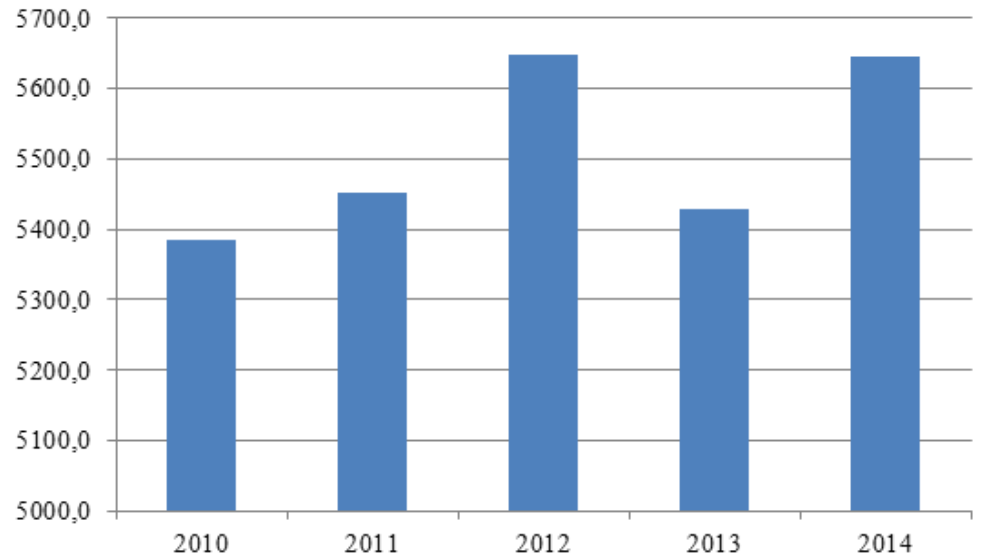

Figure 1. The number of employed in private business in Russia (in thousands of people at the end of the year)

Source: compiled by the authors.

At the same time, the problem of instability of infrastructural maintenance of small business against the backdrop of the uncertainty of the economic situation forcing entrepreneurs "turn off" their activities, and sometimes go to the shadow / informal economy. According to the Russian Federal Service of State Statistics (Small and medium business in Russia. 2015), in 2013 there was a sharp reduction in the number of individual entrepreneurs (Fig. 1). However, stop the activity individual entrepreneurs did not go to work for wages. This is evidenced by statistics on the employment of small, medium and large enterprises. The average number of employees in small and medium-sized businesses in 2013 also decreased by $1.7 \%$ compared to the level of c 2012 (Small and medium business in Russia. 2015).

Because of this, questions of creation of the business environment that encourages entrepreneurial activity and entrepreneurial initiatives are of particular importance. Traditionally, in the world is a whole range of measures regulated by the state: to provide financial support to small and medium-sized enterprises; assistance in obtaining government contracts; consulting services; providing information on market conditions and performance of expert advice, training, start-up entrepreneurs.

Similar measures have been developed in Russia. In the context of recent initiatives of the Government of the Russian Federation Agency for Strategic Initiatives, engaged in the development of the business environment has intensified activity. It created the Federal Corporation for the Development of Small and Medium Business. Government declaration for small business guarantee of stable tax and other basic conditions and etc.

\section{Tax incentives for small businesses}

Tax incentives for the development of small businesses directly and primarily carried out through special tax regimes (Main directions ..., 2016). 
In modern Russia, apart from the general tax regime for individual entrepreneurs following special tax regimes introduced: (a simplified tax system (STS), replacing three tax, patent tax system (the cost of a patent depends on the activity of the individual entrepreneur); single agricultural tax (UAT), while where an individual entrepreneur pays an amount of $6 \%$ of the difference between income and expenditure; a single tax on imputed income (UTII), in which the individual entrepreneur pays an amount of $15 \%$ of imputed income, regardless of the amount of revenue the state tax policy allows simultaneous use. individual entrepreneurs several special modes for the different activities.

To improve the effectiveness of tax stimulation of the development of small business in Russia is currently in the special tax treatment made changes. At the first, the expansion of the list of activities in respect of which can be applied the patent system of taxation. At second, the distribution of the rights to the use of 2-year «tax holiday» under the simplified system of taxation and the patent system of taxation on activity in the personal services sector. At third, the provision of subjects of the Russian Federation the right to reduce the tax rate for taxpayers who use the simplified taxation system with the object of taxation in the form of income: 6 to 1 per cent, depending on the categories of taxpayers and business activities. Fourth, it is given the right to lower rates of the single tax on imputed income from 15 to 7.5 percent, depending on the categories of taxpayers and types of business to representative bodies of municipal entities, legislature Federal Cities.

For self-employed persons of particular significance is the patent tax system, which allows to pay the tax and mandatory payments of insurance contributions to state extra-budgetary funds on the principle of "single window" at the same time with the registration in the appropriate quality.

\section{Analysis and assessment of the impact of special tax regimes in the level of entrepreneurial activity}

The research is based on the hypothesis that different special tax regimes have non-identical impact on the level of entrepreneurial activity. Special tax regimes, combined with the actual conditions of individual entrepreneurs, as well as many contributing factors can form a special business environment, which in varying degrees, is suitable for business purposes, varying in the range of extremely unfavorable to very favorable.

Giving due importance to the fact that the business environment is the result of a complex system of multiple interacting factors to accomplish the objectives of the study it is advisable to limit ourselves to the most significant factors. The authors identified the following factors in this capacity to assess the impact of special tax regimes in the level of entrepreneurial activity: the average amount of the tax that is attributable to a taxpayer (individual entrepreneur) (Y); the number of taxpayers (individual entrepreneurs), submit a tax return for the tax $(\mathrm{X})$; the amount of tax that is payable to tax authorities $(\mathrm{Z})$.

Official statistical information is available in the public domain at the present time is to these factors. As it is impossible to get a complete, reliable and comparable data in the context of the subjects of the Russian Federation for all special tax regimes: STS, UAT and UTII except patent taxation system (official statistics are available only on the following parameters: the number of individual entrepreneurs, applying the patent system tax, and issued patents for the right use of business activities (Report on form № 1-PATENT)).

The data in the context of the subjects of the Russian Federation for the special tax regimes are presented on the website of the Federal Tax Service in the following reports: report on the tax base, and the structure of charges for the tax paid in connection with the use of a 
simplified tax system (Report on Form №5-STS); statement of the tax base, and the structure of charges for the unified tax on imputed income for individual activities (Report on Form №5-UTII); statement of the tax base and structure of charges on a single agricultural tax (Report on Form №5-UAT) for a number of years. This study used data as of 01.01.2016, in the context of the Russian Federation for the special tax regimes: STS, UAT and UTII.

Analysis and assessment of the impact of special tax regimes in the level of entrepreneurial activity carried out using the method of regression analysis: developed models of interaction factors studied and calculated correlation coefficients, characterizing the influence of variations in the factors in pairs - XY, XZ and YZ.

The most important results of the study are presented in the table 1 and graphs (Fig.2-4).

Table 1. Estimated value of the correlation coefficient, which characterizes the influence of special tax regimes for entrepreneurial activity in Russia as of 01.01.2016

\begin{tabular}{|c|c|c|c|}
\hline \multirow{2}{*}{ Special tax regimes } & \multicolumn{2}{|c|}{$\begin{array}{c}\text { The correlation coefficient, which characterizes the influence of variations in } \\
\text { factors }\end{array}$} \\
\cline { 2 - 4 } & XY & XZ & YZ \\
\hline STS & -0.304 & 0.884 & -0.024 \\
\hline UAT & 0.220 & 0.961 & 0.364 \\
\hline UTII & 0.395 & 0.863 & 0.587 \\
\hline
\end{tabular}

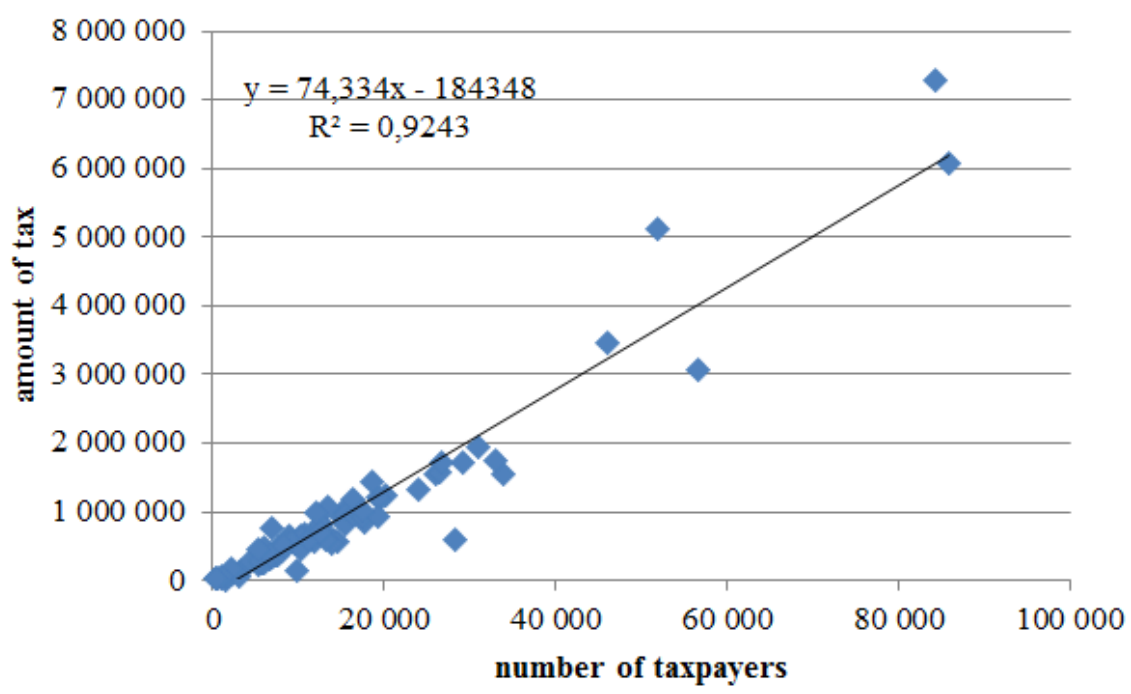

Figure 2. Relationship number of taxpayers (individual entrepreneurs), submit a tax return for the tax, and the amount of the simplified tax system, to be paid to the budget of Russia as of 01.01.2016.

Source: compiled by the authors.

The study found a strong positive correlation between the variation of the number of taxpayers (individual entrepreneurs), submit a tax return for the tax, and the variation of total taxes (for each tax separately), payable to the budget.

Analysis of the results of the study also allows us to conclude that in Russia as of 01.01.2016, the impact of special tax regimes for entrepreneurial activity is different. Thus, the variation of the average amount of tax attributable to a taxpayer (individual entrepreneur) tax such as STS and UAT has a positive effect on the variation of the number of taxpayers (individual entrepreneurs), submit a tax return for the tax. The correlation coefficient, which characterizes the relationship between the variation of the average amount of the tax attributable to a 
taxpayer (individual entrepreneur) and the variation of the number of taxpayers (individual entrepreneurs), submit a tax return for the tax made on STS and UAT respectively 0.220 and 0.395. This allows you to witness the positive relationship respectively weak and medium strength (on a scale Cheddok).

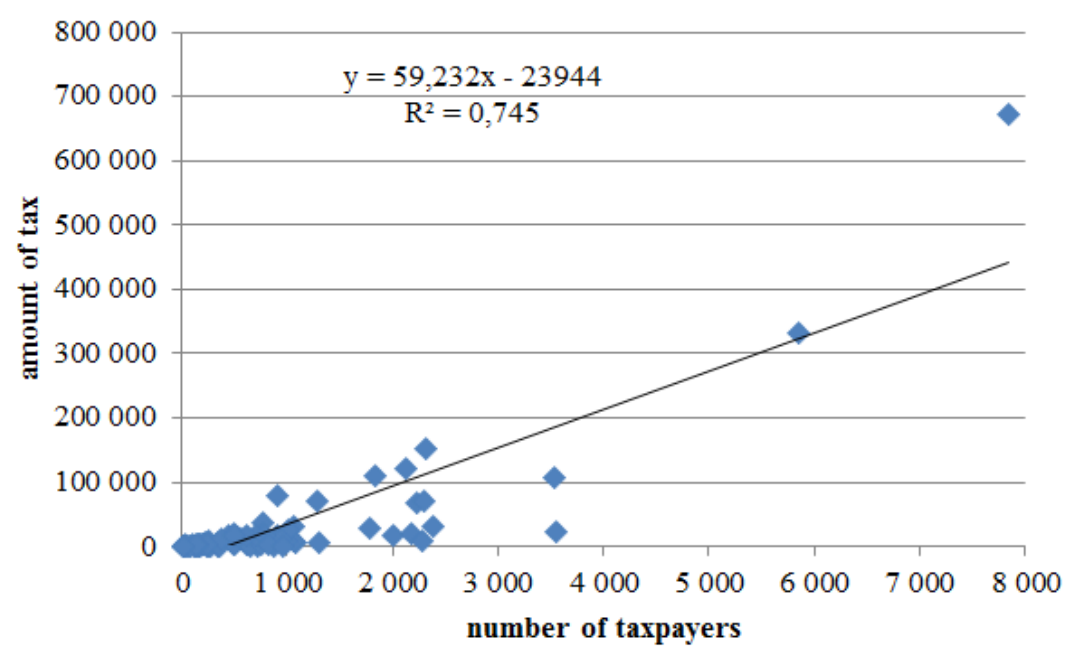

Figure 3. Relationship number of taxpayers (individual entrepreneurs), submit a tax return for the tax, and the amount of the unified agricultural tax system, to be paid to the budget of Russia as of 01.01.2016.

Source: compiled by the authors.

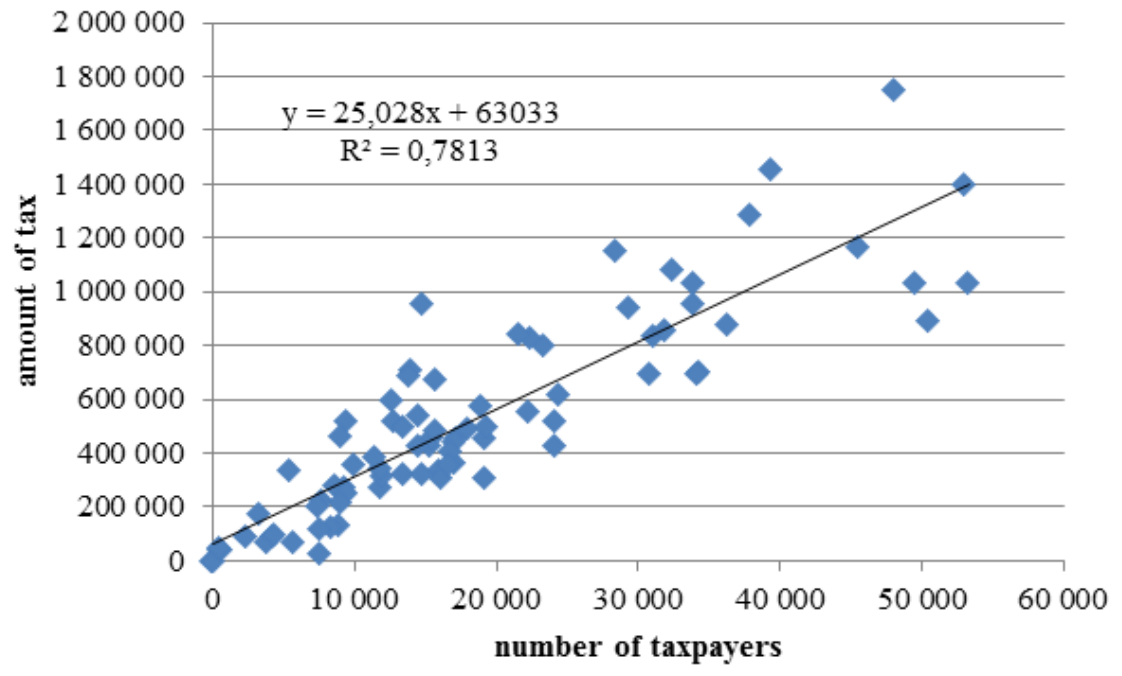

Figure 4. Relationship number of taxpayers (individual entrepreneurs), submit a tax return for the tax, and the amount of the single tax system on imputed income, to be paid to the budget of Russia as of 01.01.2016.

Source: compiled by the authors.

The situation developing with these indicators on UTII, exactly the opposite is already considered by STS and UAT. The correlation coefficient, which characterizes the relationship between the variation of the average UTII amounts attributable to a taxpayer (individual entrepreneur) and the variation of the number of taxpayers (individual entrepreneurs), tax returns submitted by UTII was -0.304 , which allows to draw a conclusion about the negative impact of moderate strength (on a scale Cheddok). Therefore, the authors put forward a hypothesis is completely confirmed. 
It should also be noted that the entrepreneurial activity is not constant at different times, and also has different intensity in different regions of the country. Therefore, it is necessary to consider the development of measures of state regulation in the segment of individual entrepreneurship.

\section{Conclusions}

A study conducted by the authors, leads to the following conclusions. Small business is the basis of qualitative transformations of modern Russia, to innovative competitive economy, a high level of employment, the creation of the middle class. It is necessary to strengthen the regulatory role of the state, the creation of adequate institutional provision, because the existing complex of small business support measures does not form an integral system into effect fragmentation objectives and inconsistency regulators. It is important not only to improve the conditions of doing business, but also practice of applying legislation. Impact of special tax regimes for entrepreneurial activity different: the influence of the variation of individual factors on the change of business activity, and the STS and UAT positive and UTII - negatively. The use of special tax regimes is not the only condition for stimulating entrepreneurial activity. However, their influence is quite significant, so their use in conjunction with other institutional changes will yield the best results.

\section{References}

Main directions of tax policy of the Russian Federation for 2016 and the planning period of 2017 and 2018.

Available on-line at http://www.consultant.ru/document/cons_doc_LAW_183748/

(12.09.2016).

OECD Economic Survey: Russian Federation, January 2014.

Available on-line at http://www.oecd.org/eco/surveys/Overview_ RUSSIARus_2013.pdf (10.09.2016).

Report on form number 1-PATENT "Report on the number of individual entrepreneurs, applying the patent system of taxation, and issued patents for the right to use the patent system of taxation in the context of business activities" as of 01.01.2016 on the subjects of the Russian Federation

Available on-line at https://www.nalog.ru/rn78/related activities/statistics_and_analytics/forms/6146945/ (05.09.2016).

Report on form number 5-STS as of 01.01.2016, in the context of the Russian Federation. Report on the tax base, and the structure of charges for the tax paid in connection with the use of a simplified tax system

Available on-line at https://www.nalog.ru/ rn78/related_activities/statistics_and_analytics/forms/6105035/(05.09.2016).

Report on form number 5 UAT as at 01.01.2016, in the context of the Russian Federation. Report on the tax base and structure of charges on a single agricultural tax

Available on-line at https://www.nalog.ru

/rn77/related_activities/statistics_and_analytics/forms/6087211/ (05.09.2016).

Report on form number 5 UTII as of 01.01.2016, in the context of the Russian Federation. Report on the tax base, and the structure of charges for the unified tax on imputed income for certain types of activities 
Available on-line at https://www.nalog.ru/

rn78/related_activities/statistics_and_analytics/forms/6079202/(05.09.2016).

Small and medium business in Russia. 2015

Available on-line at

http://www.gks.ru/wps/wcm/connect/rosstat_main/rosstat/ru/statistics/publications/catalog/do

c_1139841601359 (10.09.2016).

Strategy of development of small and medium business in the Russian Federation for the period up to 2030. Approved by Decree of the Russian Government 02.06.2016 № 1083-p, available on-line at

http://government.ru/media/files/jFDd9wbAbApxgEiHNaXHveytq7hfPO96.pdf (11.09.2016). 